\title{
Slum Rehabilitation Planning and Analysis Using AUTOCAD and GIS in Greater Visakhapatnam Municipal Corporation, Andhra Pradesh
}

\section{Krishna Sumanth", B Sridevi and R Stephen Babu \\ Raghu Institute of Technology, Dakamarri, Visakhapatnam, Andhra Pradesh, India}

*Corresponding author: M Krishna Sumanth, Raghu Institute of Technology, Dakamarri, Visakhapatnam, Andhra Pradesh, India, Tel: 9618604623; E-mail: sumanthmadineedi@gmail.com

Rec date: November 14, 2017; Acc date: November 23, 2017; Pub date: November 27, 2017

Copyright: ( 2017 Krishna SM, et al. This is an open-access article distributed under the terms of the Creative Commons Attribution License, which permits unrestricted use, distribution, and reproduction in any medium, provided the original author and source are credited.

\begin{abstract}
Now-a-days one of the major concerns of urbanization is informal settlements also called slums. Accelerating urban growth is resulting in unprecedented and increasing numbers of impoverished people living in unacceptable conditions. Urbanization in developing world is unprecedented and in coming few years the number of urban dwellers is expected to exceed rural dwellers.

Visakhapatnam, one of the major cities in Asia is a huge victim of such settlements. It poses a great threat for the growth of the city in both in industrial as well as urban aspects. The main objective of the present study is to study the reasons for the rapid growth of slums in and around Visakhapatnam and to suggest suitable planning strategies to curb the unacceptable conditions existing at those places and to propose suitable plans using AUTOCAD for some of those areas. The study also involves the identification of major slum areas in and around Greater Visakhapatnam Municipal Corporation using remote sensing images and with the aid of software like EI Shayal Smart Online and also mapping land-use and land-cover patterns with the help of ARC GIS.
\end{abstract}

Keywords: Slum; Urbanization; GVMC; GIS; Remote sensing

\section{Introduction}

Visakhapatnam, a potential industrial and port city in India, a recreational and tourism hub of Andhra Pradesh is giving high scope for formation of slum areas which in turn to be developed where even minimum conditions for living standards are not met. Almost all the areas of Greater Visakhapatnam Municipal Corporation (GVMC) consist of slums. There is no particular boundary for slums and dynamic changes in existing slum areas occurring because of migrations from rural areas. Most of these slums in the greater Visakhapatnam municipal Corporation are not recognized by government [1-3]. It is not easy to identify all the slums and calculate the area with boundaries for development. So, the potential areas for development can be easier by making use of Geographic Information System (GIS) and Remote Sensing applications and by therefore developing layout for those slums becomes much easier.

Thus, throwing light on the possible strategic approaches that can be adopted in the field of urban development process for a better sustainable solution.

- Under Section-3 of the Slum Area Improvement and clearance Act, 1956, slums have been defined as mainly those residential areas where dwellings are in any respect unfit for human habitation by reasons of dilapidation, overcrowding, faulty arrangements and designs of such buildings, narrowness or faulty arrangement of streets, lack of ventilation, light, or sanitation facilities or any combination of these factors which are detrimental to the safety, health and morals.

- Experts at a UN-HABITAT meeting held in 2002 agreed on the following definition: "A slum is a contiguous settlement where the inhabitants are characterized as having inadequate housingand basic services. A slum is often not recognized and addressed by the public authorities as an integral part of the city."

\section{Methodology}

\section{Location of study area}

The study area is located in between $17^{\circ} 32^{\prime} 30^{\prime \prime}-17^{\circ} 52^{\prime} 30^{\prime \prime}$ northern latitude and $83^{\circ} 04^{\prime} 30^{\prime \prime}-83^{\circ} 24^{\prime} 30^{\prime \prime}$ eastern longitude with an area of 545 sqkm. The city is abutting Bay of Bengal on the eastern side, Duvvada hills on the western side, YaradaKonda on the southern side and Madhurawada dome is on the Northern side. The entire urban agglomeration is located in a saucer shape basin of Visakhapatnam. YaradaKonda reserved forest has been highly affected by Naval and Industrial activities, whereas a beautiful park has been developed over the Kailasagiri with sea view. Simhachalam an abode of Lord Narasimha swami is located on the other end of the Kailasagiri hill range.

\section{Land use/land cover for the study area}

Land use describes how a piece of land is used whereas land cover describes the materials present on the surface (Sabins). In other words, the term "land cover "relates to the types of features present on the surface of the earth, and "land use" relates to the human activity associated with a specific piece of land.

The word "land use" describes how a parcel of land is being used. This has been related to economic activity and often it can be changed. Land cover denotes the permanent features such as water bodies, rockiness, forest lands, etc. These are more or less permanent features. Within the land cover often land use may take place. 
Page 2 of 4

The overall objective of image classification procedure is to automatically categorize the pixels in an image into land use/land cover classes. Normally, multispectral data are used to perform such a classification. The spectral pattern present with in data for each pixel is used as the numerical basis for categorization. In this analysis, both digital and visual interpretations of land use/land cover have been carried out. However, only visual interpretation thematic map has been used in GIS analysis. The land use/land cover categories delineated from the study area are Built-upland, Deciduous Dense/ Reserved Forest, Scrub/Degraded forest, Fallow land, Marshy land, Water body, Reservoir, Agriculture land, Beach sand, Mangroves, Plantations, Scrub lands (Table 1).

A sudden change in land use/land cover may be indicative of change in terrain character. The land use pattern and land management of an area reveal indirectly the conditions of the people of the area, their economic status and resources. The information for land use planning comprises of reliable up-to-date and comprehensive data on physical, ecological and socioeconomic frame work of a region. National land use/land cover classification for India, which is fairly compatible with user's needs, was developed by land use/land cover division under National Remote Sensing Agency [4-6]. The land use/land cover analyses were carried out following the standard visual interpretation techniques as suggested by NRSA.

\begin{tabular}{|l|l|}
\hline Land use/Land cover Classes & Area in $\mathbf{( k m}^{2} \mathbf{~}$ \\
\hline Sandy area & 11.37 \\
\hline Marine Water & 2.23 \\
\hline Deciduous Forest & 101.11 \\
\hline Defense Area & 5.31 \\
\hline Evergreen Forest & 4.14 \\
\hline Industrial Area & 32.7 \\
\hline Fallow land & 107.48 \\
\hline Plantation & 44.62 \\
\hline Gullied Land & 26.1 \\
\hline Reservoir & 8.77 \\
\hline Rural Area & 3.27 \\
\hline Scrub Land & 31.71 \\
\hline Urban Area & 135.14 \\
\hline Marshy Land & 6.14 \\
\hline
\end{tabular}

Table 1: Identified Land use/Land cover classes in the study area.

\section{Results and Discussion}

Visakhapatnam is one of the cities in India that figure among the 30 cities selected for the implementation the Rajiv Awas Yojana (RAY), a housing scheme aimed at hut less cities. The slums will be developed in situ and funds will be allocated for development of infrastructure. The model of the housing unit and funding has not been finalized, according to Municipal Commissioner V.N. Vishnu who participated in a meeting organized to discuss draft policy guidelines at Udaipur. The RAY plans to make these cities hut less in five years by developing houses in ' $G+3$ ' and " $G+2$ " model for dwellers in slums where they are living now. Visakhapatnam has a total of 171 slums. The new housing scheme should be integrated with the city development plan already prepared by GVMC (Figure 1).

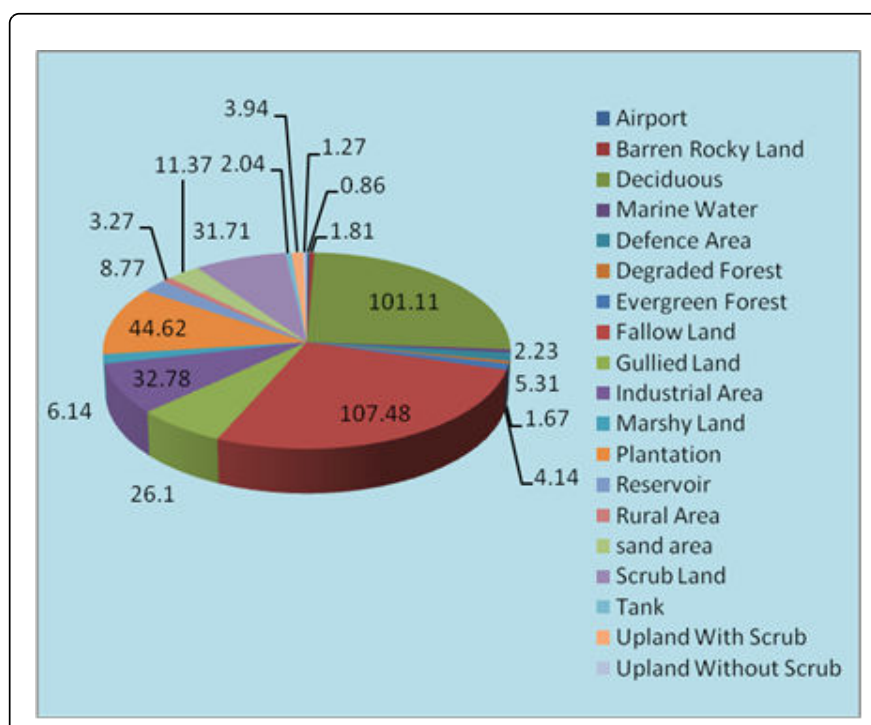

Figure 1: Percent areas of different types of land use/land cover classes.

\section{Existing slum area assessment in study area}

Visakhapatnam is in the first place in India with highest percentage of slum households. According to census-2011 there are $44.1 \%$ households present in the slums when compared with Total Urban households in Greater Visakhapatnam Municipal Corporation (GVMC). At present 171 slums are recognized in the study area of Greater Visakhapatnam Municipal Corporation (GVMC). Those slums are systematically classified into three categories namely Normal slums, vulnerable slums and Replaceable slums.

The present study takes into account four major slums in Greater Visakhapatnam Municipal Corporation. They include

- Sri Krishnapuram,

- Bakkannapalem,

- Suryateja Nagar,

- Durga Nagar.

The total areas of the slums and the category they belong to are mentioned in the following Table 2.

\begin{tabular}{|l|l|l|l|}
\hline S.no & Name & Area $\left(\mathbf{m}^{2}\right)$ & Slum type \\
\hline 1 & Sri Krishnapuram & 7204.52 & Normal \\
\hline 2 & Bakkannapalem & 33133.898 & Normal \\
\hline 3 & Suryateja Nagar & 10884.5 & Normal \\
\hline 4 & Durga Nagar & 18357.9 & Vulnerable \\
\hline
\end{tabular}

Table 2: Category and Areas of Different Slums. 
Citation: Krishna SM, Sridevi B, Stephen BR (2017) Slum Rehabilitation Planning and Analysis Using AUTOCAD and GIS in Greater

Page 3 of 4

\section{Slum rehabilitation plans}

The planning of urbanization of slums is carried out with the help of AUTOCAD software. In the planning process, $70 \%$ of the total households is considered and is intended to receive a single dwelling. The planning of dwellings is done following the byelaws proposed by the Governmental Organizations. All the areas of the slums are calculated approximately and are planned accordingly. Greenery is given due importance during the planning process due to the environmental concern. Factors like number of households in the respective slums, sanitary conditions, provision of drinking water, drainage conditions and provision for future development are taken into consideration while planning. The detailed plans for different slums are as follows:

\section{Suryateja Nagar}

Total number of households $=225$,

Total Population=1013,

Total area of Suryateja Nagar=3.1 acres,

Total area of Suryateja Nagar (in sq. m) $=12174.765 \mathrm{~m}^{2}$,

Existing soil type in the slum is brown clay soil.

Accordingly, the Suryateja Nagar slum was divided into number of dwelling units. The detailed analysis as follows (Table 3):

\begin{tabular}{|l|l|l|}
\hline Area of & Area in $\mathbf{~}^{2}$ & Percentage \\
\hline Residential & 6923.24 & $56.86 \%$ \\
\hline Commercial & 68.91 & $00.56 \%$ \\
\hline Facilities & 68.73 & $00.56 \%$ \\
\hline Green area & 2394.12 & $19.66 \%$ \\
\hline Roads & 2174.75 & $17.86 \%$ \\
\hline Open / Others & 545.01 & $04.47 \%$ \\
\hline Total & 12174.765 & $100 \%$ \\
\hline
\end{tabular}

Table 3: Breakup of Suryateja Nagar proposed layout.

\section{Details of the proposed layout}

Total number of plots $=177$,

Ground floor dwelling units $=150$,

G+1 dwelling units $=27$,

Total number of dwelling units $=204$,

Total estimated cost for the construction=1108 lakhs (Figure 2).

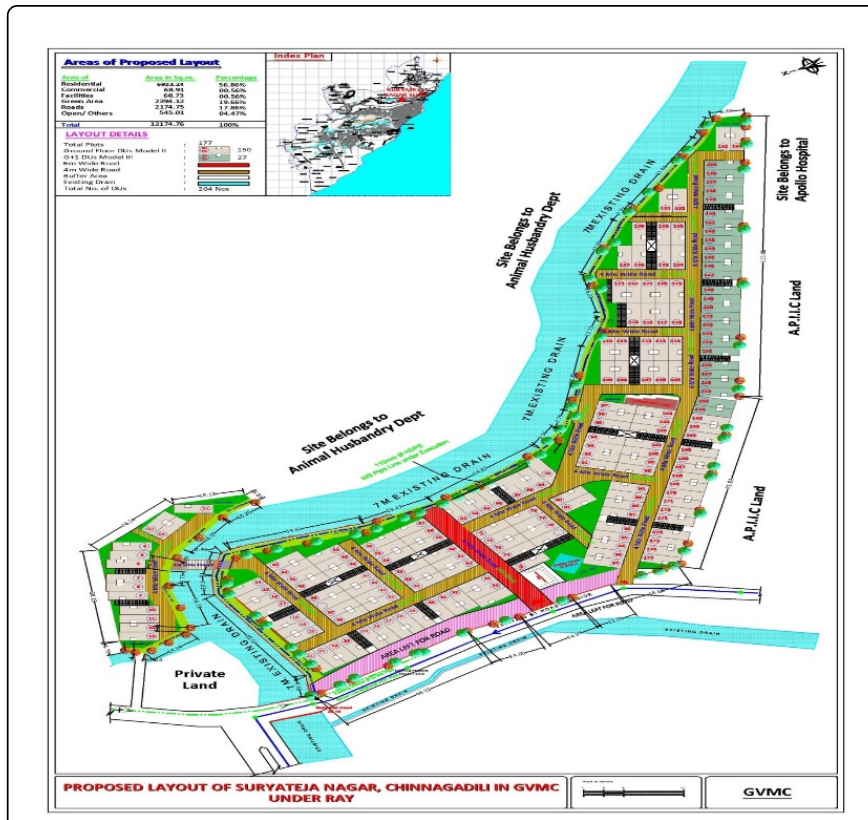

Figure 2: Proposed Suryateja Nagar Layout.

\section{Summary and Conclusions}

Slum Rehabilitation is a procedure for the development of slums which are predominantly increasing in many developing metropolitan cities. Visakhapatnam, one of the proposed Smart cities, has a vast scope for rapid industrialization as well as urbanization. Visakhapatnam is also a city with most number of slum residents when compared to its total population in our Incredible India has far more brighter chances of getting hurdles through these unwanted and unavoidable slums during its expansion. According to census 2011 there are $44.1 \%$ households present in the slums when compared with Total Urban households in Greater Visakhapatnam Municipal Corporation (GVMC). From the study it is observed that 171 slums are recognized in the study area of Greater Visakhapatnam Municipal Corporation (GVMC) which in turn poses a great threat for the city's expansion.

Accordingly, four such slum areas are considered and detailed plans for the development of those slums are proposed using AUTOCAD. Those plans take into consideration several amenities to be provided for those slums such as drinking water, proper sanitation, road networks.

The studied slums include suryateja nagar, Durga nagar, Bakkannapalem and Sri Krishnapuram. Plan for those slums are proposed in the study using AUTOCAD.

The main objective of this work is to study the existing scenario of slum dwellers and based on that provide suitable housing strategies for the slum dwellers. In this study rehabilitation of the existing slum pocket is considered as a future scope at that place. This study is mainly focus on the choice of slum dwellers as follow:

- House will be nearby their work place.

- They will be provided transportation facilities. 
Citation: Krishna SM, Sridevi B, Stephen BR (2017) Slum Rehabilitation Planning and Analysis Using AUTOCAD and GIS in Greater

Page 4 of 4

As is evident from our study, the current zoning and the related ratios, fail to address the tremendous variation in cost of land and tenement densities that occur in slum settlements across the zones. To make the projects viable for all, it would be desirable to tie every project to local parameters like tenement density and cost prevalent on that site. The beneficiary families must contribute at least $20 \%-25 \%$ of the total cost. Our studies have shown that it is quite possible for families to service an interest in the range of Rs.500- Rs.1000 per month. High-rise buildings are very energy intensive. The crumbling infrastructure of the cities compound problems for especially the poor as they are worst affected when electricity fails, and water cannot be pumped up apart from being very hard on children and the old. Commercial development on the same site along with a slum rehabilitation component should be avoided as far as possible. It would be prudent to note here that $40 \%$ of the city's population is in slums, which occupies less than $5 \%$ of the total land in the city. Hence commercial development in these pockets could be avoided altogether. The city must safeguard the interest of the poor and prevent vertical slums, which would be more disastrous for the city in future. There are ample evidences of failed projects worldwide. As the rules stand now it is mandatory for the slum dwellers to participate in the SRA scheme. A participatory approach will lead to a more sustainable project. Mechanisms need to be created which would allow all stakeholders to meet regularly to work out issues, which cause impediments, and bring transparency in the system. This would also help avoid victimization of stakeholders by vested interests.

\section{References}

1. Water Aid (2008) Tackling the silent killer: The case for sanitation.

2. WHO (2008) Safer Water, Better Health: Costs, Benefits and Sustainability of Interventions to Protect and Promote Health.

3. World Bank (2008) Environmental health and child survival: epidemiology, economics, experiences. World Bank.

4. David EW (2008) A Brief Overview of the History of CAD.

5. David EW (2006) Autodesk and AutoCAD.

6. Zee News (2013) Norms for housing for slum dwellers eased by Delhi govt. 